\title{
Evaluation Method of Bending Deformation Capacity of RC Piles under Confining Pressure in the Ground
}

\author{
Toshinari IMAMURA \\ Researcher, \\ Yoshitaka MURONO, Dr. Eng. \\ Senior Researcher, \\ Earthquake and Structural Engineering Laboratory, Structures Technology Division
}

Masahiro SHINODA, Ph.D.

Section Chief,

Integrated Geotechnology Institute Limited, Engineering Department

(Formerly a Guest Researcher of the Railway Technical Research Institute)

Tomohiro KAWANISHI

Researcher,

Earthquake and Structural Engineering Laboratory, Structures Technology Division

\begin{abstract}
$R C$ piles are subject to confining pressure from the subgrade, meaning that their deformation capacity is likely to be greater than that demonstrated under atmospheric conditions. The purpose of this study is to establish a simplified evaluation method for the ductility of RC piles that are subject to confining pressure from subgrade reaction. We proposed a method of calculating this ductility with the confining pressure from subgrade reaction converted into an equivalent confining pressure from hoop reinforcements. We then conducted alternate loading tests for RC piles in a pressurizing soil-filled chamber. Finally, we compared these experimental results with those achieved through numerical simulation using the newly developed method, and demonstrated its validity.
\end{abstract}

Keywords: confining pressure, RC piles, bending deformation characteristic, simplified evaluation method, pressurizing soil-filled chamber, alternate horizontal loading tests

\section{Introduction}

In seismic design against major earthquakes, it is essential to evaluate the bending deformation capacity of structural members appropriately.

Numerous researchers have performed a range of loading experiments using full-scale or reduced-scale models to understand the bending deformation capacity of reinforced concrete, and the following points have been clarified 1) 2) 3) 4) (1) If lateral confining reinforcements are closely arranged, the compressive buckling or swelling of longitudinal reinforcements is controlled. The ductility of the member is therefore greatly improved due to the confining effect on the concrete core. (2) Cover concrete also controls compressive buckling or swelling in longitudinal reinforcements.

In addition, a number of methods for evaluating the ductility of RC members have been proposed as follows: (1) An RC member is modeled using a beam element, and the bending deformation characteristic at element level is given by an empirical formula based on a large number of alternate loading experimental results ${ }^{1)}{ }^{5)}$. (2) The bending deformation capacity of the member is calculated using a fiber element or a finite element, applying the constitutive law to reinforcement and concrete ${ }^{4)}$. In the publication The Seismic Design Standard for Railway Structures, we have adapted the former method because of its simplicity in structural calculation ${ }^{5)}$. Specifically, we defined the length of an equivalent plastic hinge as $1 D$ (where $D$ is the height of the member), and proposed an empirical formula to evaluate the ductility of structural members in a form of the rotational angle or the average curvature of the plastic hinge, based on the results of a large number of alternate horizontal loading tests for cantilever RC columns under atmospheric conditions.

$\mathrm{RC}$ piles embedded in the ground are different from those under atmospheric conditions in the following respects: (1) The distribution of the bending moment exhibits a curved profile. (2) Cover concrete does not detach easily after peeling from the concrete core due to the presence of the surrounding ground. (3) A confining pressure acts on the concrete as the ground reaction. It is therefore necessary to examine to the feasibility of applying the bending deformation capacity obtained from these studies to structural members such as piles that are subject to confining pressure from the subgrade.

The purpose of this study is to establish a rational method of evaluating the ductility of RC piles subject to confining pressure from subgrade reaction. First, we carried out triaxial compression tests on RC columns to understand the influence of confining pressure on the compressive strength and residual strain of concrete. Next, we proposed a method of calculating the ductility of RC piles in which the confining pressure from subgrade reaction is converted into an equivalent confining pressure from hoop reinforcements. Finally, we conducted alternate horizontal loading tests on RC piles in a pressurizing soil-filled chamber, and compared the experimental 
results with those obtained through numerical simulation to demonstrate the validity of the newly developed method.

\section{Triaxial compression tests for $\mathrm{RC}$ members under confining pressure}

\subsection{Experimental summary}

In this chapter, we outline the triaxial compression tests conducted on RC members to understand the influence of confining pressure from the subgrade on the stressstrain relationship of the concrete core.

The test specimen is a form of cylinder $100 \mathrm{~mm}$ in diameter and $300 \mathrm{~mm}$ high. Longitudinal reinforcements were $D 6$ and hoop reinforcements $D 4$ at a $70-\mathrm{mm}$ pitch. Test specimens were made by substituting aggregate-excluded mortar for the concrete, and we aimed for a compressive strength of $21 \mathrm{MPa}$ by the seventh day. The experimental parameters were the number of longitudinal reinforcements (four or six), the presence of cover concrete and the value of the confining pressure $(0 \mathrm{kPa}, 49 \mathrm{kPa}$ and $400 \mathrm{kPa}$ ). We carried out monotonic loading tests at a strain rate of $0.01 \% / \mathrm{min}$ up to an axial strain of $10 \%$.

\subsection{Experimental results}

Figure 1 shows the relationship of deviator stress and axial strain for the test specimen of four longitudinal reinforcements with cover concrete. Although the initial stiffness and compressive strength were influenced little by the confining pressure, the residual strength after the peak (in the axial strain range of 1-4\%) was strongly influenced by increases in the confining pressure. This tendency was also experienced in all other cases. These results confirm that RC members subject to subterranean confining pressure exhibit greater ductility than RC members under atmospheric conditions.

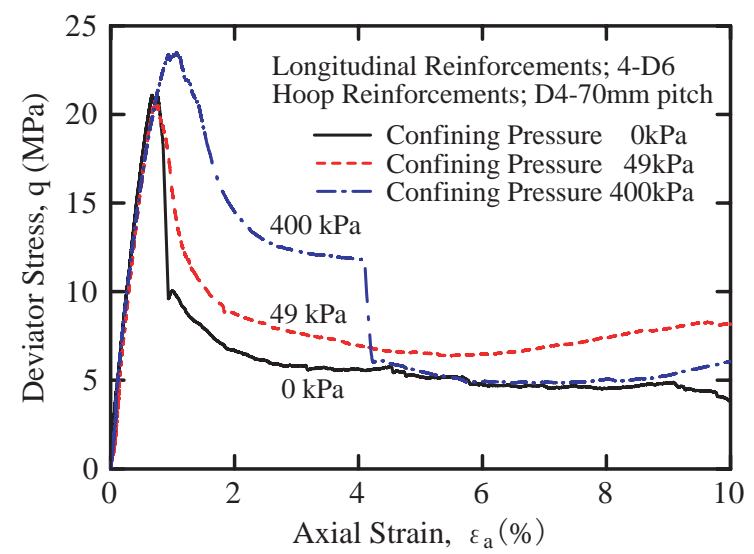

Fig. 1 Results of triaxial compression tests on RC members

3. Proposed model to evaluate the ductility of RC piles subject to confining pressure

\subsection{Basic concept}

The two confining pressures acting on the concrete
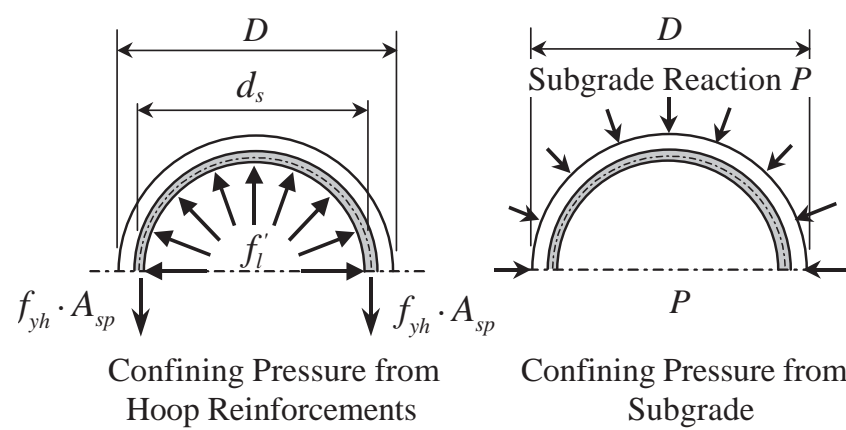

Confining Pressure from Subgrade

\section{Fig. 2 Confining pressure acting on the concrete core}

core consist of that received from hoop reinforcements and the force induced by subgrade reaction (see Fig. 2).

When RC members under atmospheric conditions are subjected to bending deformation, compression stress acts on the concrete core. The core then starts to expand horizontally, subjecting hoop reinforcements to tensile stress in the circumferential direction. By way of reaction, the concrete core receives confining pressure $f_{l}^{\prime}$ in the radial direction from the hoop reinforcements. These reinforcements therefore have the capacity to confine the concrete core as a reaction when bending deformation occurs. This confining pressure is referred to below as confining pressure from hoop reinforcements. RC piles in the ground, however, are subject to confining pressure from the surrounding soil, and this pressure always acts regardless of RC pile deformation. This force is referred to below as confining pressure from the soil.

Although there are clear differences between both types of confining pressure in affecting, there is no difference in the sense that both can confine the concrete core when the plastic hinge is formed. Moreover, if the amplitude of both confining pressures is equal, it is reasonable to assume that the ductility of RC members is also the same. Assuming then, that the confining pressure acting on the concrete core is an index of improvement in ductility, it is possible to devise a method of converting the pressure induced by subgrade reaction into the pressure from hoop reinforcements.

\subsection{Equivalent area ratio of hoop reinforcement}

In converting the confining pressure as explained above, it should be noted that there are areas of concrete core between adjacent hoop reinforcements that are ineffectively confined due to the discrete arrangement of the reinforcements at specified intervals as shown in Fig. 3. To account for this, the concept of the confinement effectiveness coefficient $k_{e}$ proposed by Mander et al. ${ }^{6)}$ was introduced. Here, $k_{e}$ is the ratio of an area of concrete core enclosed by hoop reinforcement $A_{c c}$ (strictly, one from which the sectional area of longitudinal reinforcement is subtracted) to the area of concrete core actually confined $A_{e}$, as shown in Fig. 3. This is calculated by $k_{e}=A_{e} / A_{c c}$.

For a circular cross section, if the stress distribution along the axis of the members is likely to occur in the form of a second-degree parabola (which starts from the position of the arranged hoop reinforcements with an initial tangent slope of 45 degrees), the confinement effec- 


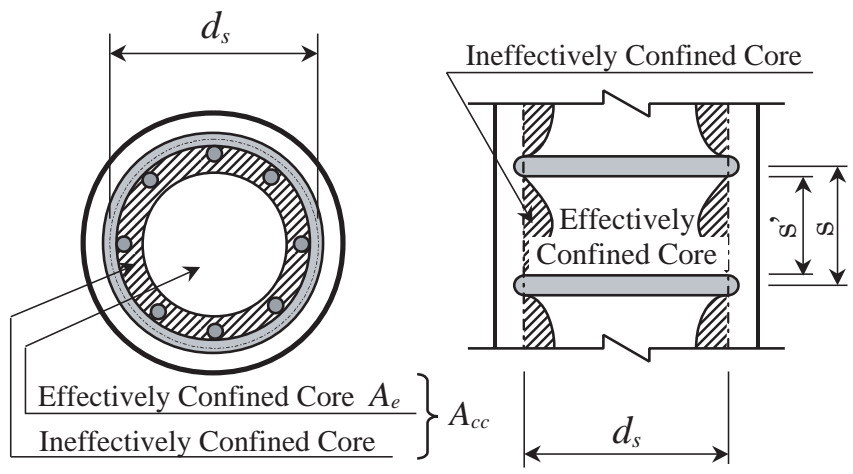

Fig. 3 Confinement of concrete core by hoop reinforcements

tiveness coefficient $k_{e}$ is obtained by

$$
k_{e}=\left(1-\frac{s^{\prime}}{2 d_{s}}\right)^{2} /\left(1-\rho_{c c}\right)
$$

where $s^{\prime}=$ the clear vertical spacing between adjacent hoop reinforcements, $d_{s}=$ the diameter of hoop reinforcements between bar centers, and $\rho_{c c}=$ the ratio of the area of longitudinal reinforcement to the area of section core.

If the concrete core enclosed within the hoop reinforcements does not have a loose region (i.e. the full cross section is confined), the equilibrium of forces between the concrete core and the hoop reinforcements is as shown in Fig. 2. From this figure, the confining pressure on the concrete core from the hoop reinforcements $f_{l}$ is obtained by

$$
f_{l}=\frac{2 f_{y h} \cdot A_{s p}}{s \cdot d_{s}}
$$

where $f_{y h}=$ the yield strength of the hoop reinforcement, $A_{s p}=$ the area of hoop reinforcement, and $s=$ the centerto-center spacing of the circular hoops.

Through multiplying this by the confinement effectiveness coefficient $k_{e}$, the effective confining pressure on the concrete core $f_{l}^{\prime}$ considering the loosening region along the member's axis can be calculated. From the viewpoint of ductility improvement, it is reasonable to assume that the $f_{i}$ value calculated is equal to the confining pressure from subgrade reaction $p$. Thus, Eq. (3) is shown to be valid.

$$
p=f_{l}^{\prime}
$$

Since the area ratio of hoop reinforcement $p_{w}^{\prime}$ is defined as $p_{w}^{\prime}=\left(2 \cdot A_{s p}\right) /(D \cdot s)$, the equivalent area ratio of hoop reinforcement $p_{w}^{\prime}$ that gives the same confining pressure as the subgrade reaction is obtained by

$$
p_{w}^{\prime}=\frac{p \cdot d_{s}}{k_{e} \cdot f_{y h} \cdot D}
$$

where $D$ is the pile diameter.

\subsection{Moment-curvature relationship}

In designing a structure using the proposed momentcurvature relationship, it is important that: (1) the proposed model has the ability to represent increases in ductility smoothly and continuously from a state of zero confining pressure, and that (2) it allows simple calculation. It can then be decided that the moment-curvature rela- tionship of RC piles subject to confining pressure is expressed based on the tetra-linear model provided for the current guideline known as The Seismic Design Standard for Railway Structures ${ }^{5)}$. The rotational angle in the plastic hinge is then calculated by adding the equivalent ratio of hoop reinforcement obtained using Eq. (4) to the ratio of hoop reinforcement actually arranged.

\section{Alternate loading tests on RC piles embedded in a pressurizing soil-filled chamber}

\subsection{Experimental summary}

To verify the bending deformation characteristics of $\mathrm{RC}$ piles embedded in the ground, alternate loading tests on RC piles were conducted in a pressurizing soil-filled chamber.

Figure 4 illustrates the test apparatus. The soil-filled chamber has an inside diameter of $1,500 \mathrm{~mm}$ and is 1,950 $\mathrm{mm}$ deep. The pressurizing tank is installed around the soil-filled chamber, and the ground can be pressurized laterally through the rubber sleeve placed between the ground and the tank. Four hydraulic jacks are set up on the 20 mm-thick steel cover, enabling vertical normal stress to be exerted on the soil deposits.

The test procedure is described here. First, an RC pile was set up in a vacant chamber, and air-dried Toyoura standard sand was deposited through multiple sieves (the properties of the soil are listed in Table 1). Here, we aimed to make the relative density of the soil deposits approximately $80 \%$. Next, a steel cover was placed on top of the cham-

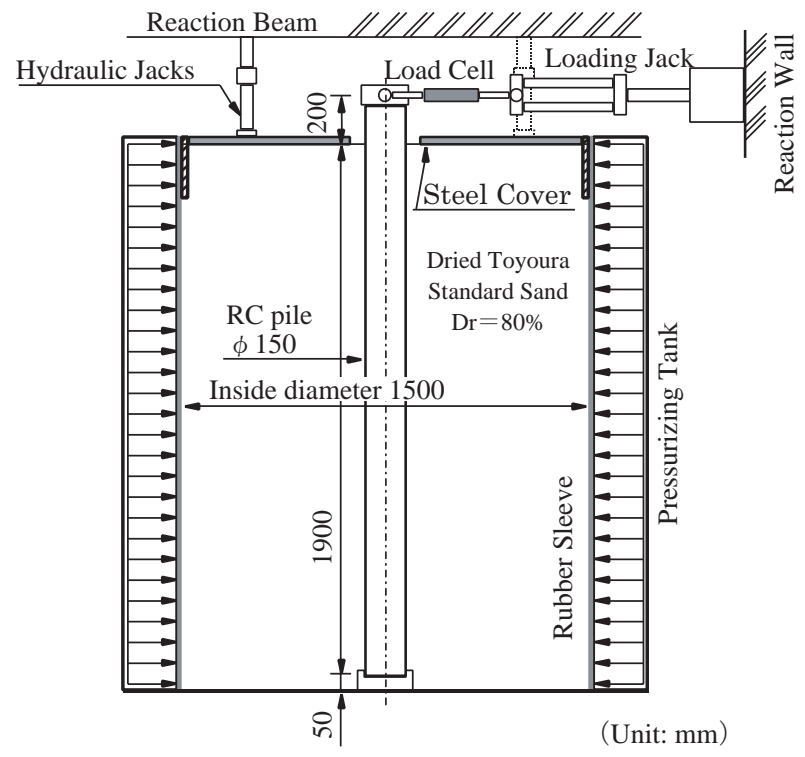

Fig. 4 Outline of test apparatus

Table 1 Properties of Toyoura standard sand

\begin{tabular}{c|c|c}
\hline $\begin{array}{c}\text { Specific gravity } \\
\text { of soil particles } \\
\rho_{\mathrm{s}}\end{array}$ & $\begin{array}{c}\text { Maximum } \\
\text { void ratio } \\
\boldsymbol{e}_{\max }\end{array}$ & $\begin{array}{c}\text { Minimum } \\
\text { void ratio } \\
\boldsymbol{e}_{\min }\end{array}$ \\
\hline \hline 2.650 & 0.978 & 0.596 \\
\hline
\end{tabular}


Table 2 Properties of reinforcements used

\begin{tabular}{c|c|c}
\hline Grade & $\begin{array}{c}\text { Tensile yield } \\
\text { strength }\end{array}$ & $\begin{array}{c}\text { Young's } \\
\text { modulus }\end{array}$ \\
\hline \hline SD295 (D6) & $342 \mathrm{~N} / \mathrm{mm}^{2}$ & $187 \mathrm{kN} / \mathrm{mm}^{2}$ \\
\hline
\end{tabular}

Table 3 Properties of concrete used

\begin{tabular}{c|c|c}
\hline $\begin{array}{c}\text { Test Cases } \\
\text { (Confining pressure) }\end{array}$ & $\begin{array}{c}\text { Compressive } \\
\text { strength }\end{array}$ & $\begin{array}{c}\text { Young's } \\
\text { modulus }\end{array}$ \\
\hline \hline $50 \mathrm{kPa}$ & $28.7 \mathrm{~N} / \mathrm{mm}^{2}$ & $15.4 \mathrm{kN} / \mathrm{mm}^{2}$ \\
\hline $200 \mathrm{kPa}$ & $28.8 \mathrm{~N} / \mathrm{mm}^{2}$ & $16.0 \mathrm{kN} / \mathrm{mm}^{2}$ \\
\hline
\end{tabular}

ber, and the ground was pressurized alternately in the vertical and horizontal directions at four stages in such a manner as to produce isotropic pressure up to the prescribed confining stress.

The RC piles in question are $150 \mathrm{~mm}$ in diameter. The longitudinal reinforcements are 8-D6, and the hoop reinforcements are $D 6$ at a $50-\mathrm{mm}$ pitch. The area ratio of the tensile reinforcements is $0.46 \%$, while that of the hoop reinforcements is $0.85 \%$. Tables 2 and 3 respectively indicate the material properties of both the reinforcements and the concrete used. Here, the Young's modulus of the concrete is approximately one-half that calculated from the general relationship between compressive strength and Young's modulus. The fact that the concrete is placed without using coarse aggregate is likely to be the cause of the lower Young's modulus value.

A pinned device was installed at the bottom of the piles to clarify the boundary conditions, and an attachment to load the horizontal force was set up above a level $200 \mathrm{~mm}$ from the soil deposit surface. The amplitude of the specified displacement at the loading point was gradually increased from $\delta_{y}$ to $n \times \delta_{y}\left(n=1,2,4,6\right.$ and 12), where $\delta_{y}$ is the displacement at the loading point when the longitudinal reinforcements arranged at 45 degrees from the loading direction have yielded. Three cycles are repeated at each specified displacement on both the positive and the negative sides. The two experimental cases examined were with the ground subjected to different confining pressure values of $50 \mathrm{kPa}$ in one case and $200 \mathrm{kPa}$ in the other.

\subsection{Experimental results}

Figure 5 delineates the load versus the displacement response at the loading point in the $200 \mathrm{kPa}$ case. Here, specific displacement $\delta_{y}$ was defined as $6 \mathrm{~mm}$, as the longitudinal reinforcement arranged at a 45-degree angle yielded when the displacement at the loading point reached $6 \mathrm{~mm}$. The horizontal resistance increased steadily as displacement increased up to $4 \delta_{y}$, and reached its upper limit under the first cycle of $6 \delta_{y}$. At this time, yielding of the soil deposits around the pile occurred at all depths from the ground surface to the plastic hinge part.

An abrupt decrease in the horizontal load was seen in the second cycle of $12 \delta_{y}$, though the same amplitude of displacement was repeated for the load. Finally, in the negative loading of the third cycle, the sound of the lon-

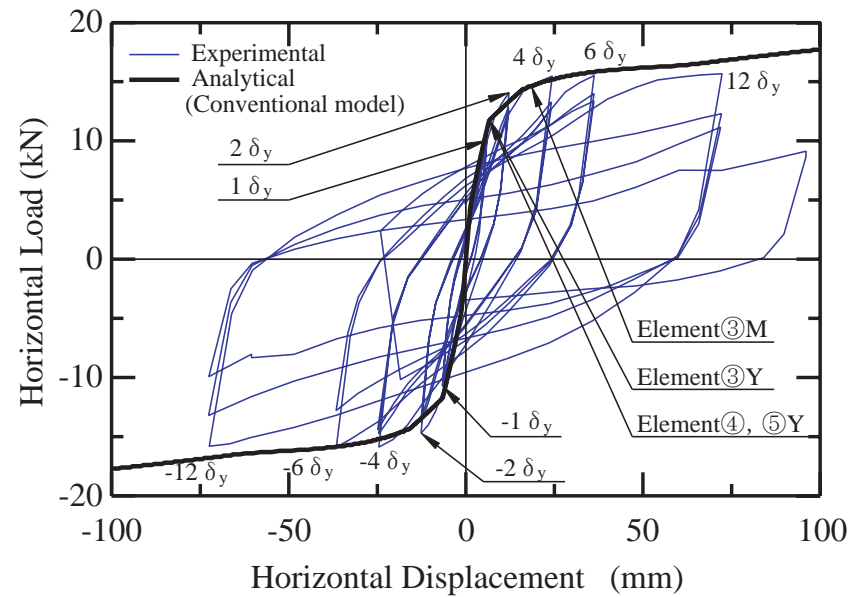

Fig. 5 Load versus displacement response $(200 \mathrm{kPa})$

gitudinal reinforcements fracturing was heard; likewise, the sound was heard again under the positive loading of $16 \delta_{y}$.

It can therefore be considered that the critical state in which the RC pile maintains maximum strength is between $6 \delta_{y}$ and $12 \delta_{y}$, because steady hysteresis loops are shown at $6 \delta_{y}$ and an abrupt decrease is observed at $12 \delta_{y}$. In the numerical simulation conducted in the next chapter, $6 \delta_{y}$ is defined as the critical displacement to enable safe evaluation of RC pile ductility in the design. In the other case of $50 \mathrm{kPa}$, the RC pile yielded when the displacement at the loading point reached $8 \mathrm{~mm}$. A steady hysteresis loop was also drawn up to $6 \delta_{y}$, and a sudden decrease in strength was observed under the second cycles of $12 \delta_{y}$.

Figure 6 illustrates the final pile crack pattern observed after excavation. In the case of $200 \mathrm{kPa}$, the longitudinal reinforcements were broken at a point $1.8 \mathrm{~m}$ from the pile tip. A number of cracks were generated at intervals of $50 \mathrm{~mm}$, the same frequency as the pitch of the hoop reinforcements. Chipping away the cover concrete revealed cracks penetrating the concrete core across a wide range of about 2 or $3 D$ ( $D$ : diameter of pile), as shown in Fig. 6. The damage area in the pile was widely distributed compared to that in the experiment under atmospheric conditions, where the damage area spanned

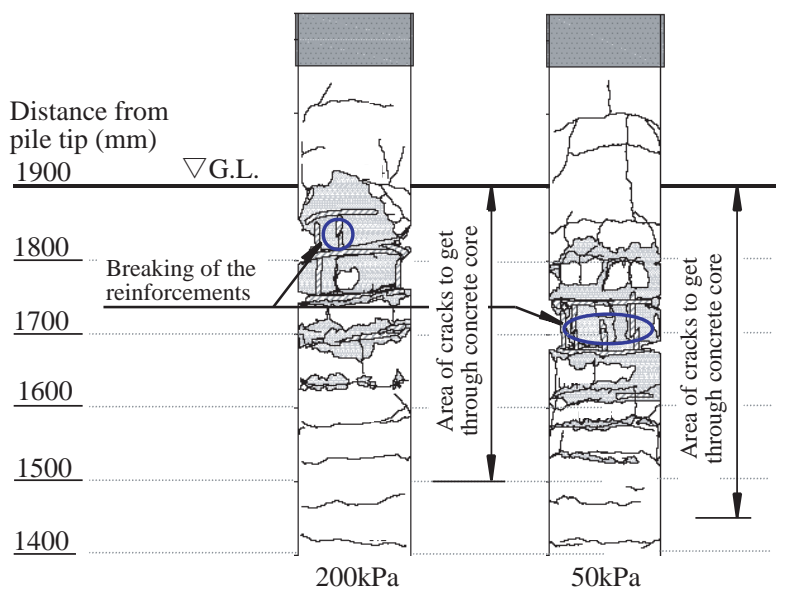

Fig. 6 Crack pattern of test specimens after excavation 
approximately $1 D$. This was considered to be a result of the ground around the member making the bending moment distribution a curve shape, and preventing the cover concrete from falling off easily.

A similar phenomenon has been reported by Shirato et al. ${ }^{7)}$, who calculated the behavior of RC piles under the ground with a fiber element. They pointed out that the plastic hinge is spread over a wide region when the confining pressure from the subgrade is taken into consideration in calculation of the cover concrete's stressstrain curve.

\section{Confirmation of effectiveness}

\subsection{Evaluation on interaction between piles and the ground}

The non-linearity of members as well as that of the ground affects horizontal displacement at the pile head. It is therefore important to express appropriately the interaction between piles and the ground in the simulation of underground pile behavior. To this end, we carried out alternate horizontal loading tests with steel pipe piles that behave in the range of elasticity using the same test apparatus, and simulated the experimental results to evaluate the non-linearity of the ground.

We evaluated the interaction between piles and the ground using the hyperbolic model shown in Eq. (5).

$$
p(y)=\frac{k_{h}}{1 / y+1 / y_{r}}
$$

where $p(y)=$ the horizontal ground reaction, $y=$ the relative displacement, and $k_{h}=$ the coefficient of horizontal subgrade reaction. $y_{r}$ indicates reference strain, and is defined by $y_{r}=p_{\max } / k_{h}$. $p_{\max }$ represents the upper limit of horizontal ground reaction, and can be substituted for the passive earth pressure for a sandy layer as described in The Seismic Design Standard for Railway Structures ${ }^{5)}$.

We calculated the coefficient of horizontal subgrade reaction $k_{h}$ based on the coefficient of subgrade reaction of beams resting on an elastic half-space ground as derived by Vesic ${ }^{8)}$. Here, we need to calculate the modulus of deformation for the subgrade $E_{h}$, because the coefficient of subgrade reaction is given as the function of it. We decided to obtain this value using the methods proposed by Koda et al. ${ }^{9)}$ and Murono et al. ${ }^{10)}$. The procedures are as follows: First, we calculated the initial modulus of elasticity for the subgrade based on the empirical formula summarized by Tatsuoka and Kohata ${ }^{11)}$ and Hardin and Richart ${ }^{12)}$, which considers the influence of stress dependency and the relative density on it. Here, it should be noted that the horizontal modulus of elasticity is less than the vertical one because sandy deposits formed by air pluviation have structural or induced anisotropy 11). We therefore multiplied the initial modulus of elasticity by a decrease coefficient of $1 / 2$. In addition, we multiplied the modulus of elasticity by another decrease coefficient of $\alpha$, which represents the influence of the ground loosening around piles that occurs in making the model ground. We decided the value of the decrease coefficient through numerical simulation of the experimental result

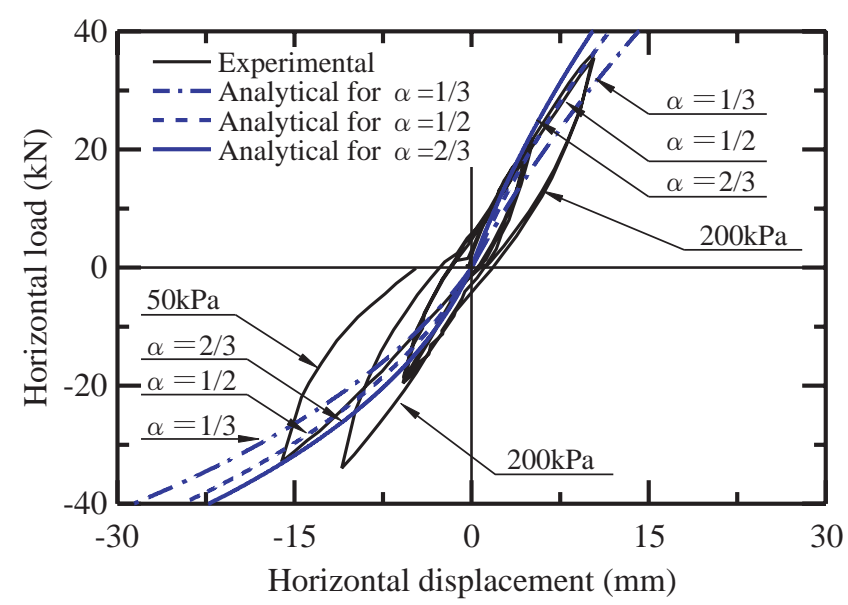

Fig. 7 Experimental and analytical results for steel pipe piles

by trial and error.

Figure 7 shows both the experimental and numerical simulation results of the steel pipe piles. The result for $200 \mathrm{kPa}$ is shown in the first quadrant, while that for 50 $\mathrm{kPa}$ is indicated in the third. We can confirm that the decrease coefficient of $1 / 2$ gives the best simulation result in both cases, and this value was therefore selected for decrease coefficient $\alpha$.

\subsection{Evaluation of RC piles under the ground}

First, we simulated the experimental result for RC piles with the tri-linear model according to The Seismic Design Standard for Railway Structures ${ }^{5}$. In this model, the moment-curvature relationship passes through the C-point (at which cracks are generated), the Y-point (at which longitudinal reinforcements yield) and the M-point (at which maximum strength is maintained). This model is referred to below as the conventional model, and Figure 5 presents the simulation results. As can be seen, the RC pile enters the M-point state when the displacement reaches approximately $3 \delta_{y}$. However, the experimental results show a stable hysteresis curve up to at least $6 \delta_{y}$. It can therefore be concluded that the conventional model underestimates the experimental results.

The results outlined above confirm the following phenomena: (1) the plastic hinge expands over a wide section of the RC pile in comparison with the results of testing conducted under atmospheric conditions. (2) The concrete core of the RC pile is subject to confining pressure from subgrade reaction. In consideration of these factors, we adopt the following two measures (this method is referred to below as the proposed model): (1) Although measures such as a small increase in the Y-point of the moment-curvature relationship are recommended in The Seismic Design Standard for Railway Structures to prevent the plastic hinge from spreading out over a range more than $1 D^{5)}$, this measure was waived to make the hinge spread out according to the shape of the bending moment distribution. (2) We converted the confining pressure on the concrete core induced by subgrade reaction into an equivalent confining pressure from hoop reinforcements to consider the confining effect outlined in Chapter 3. 


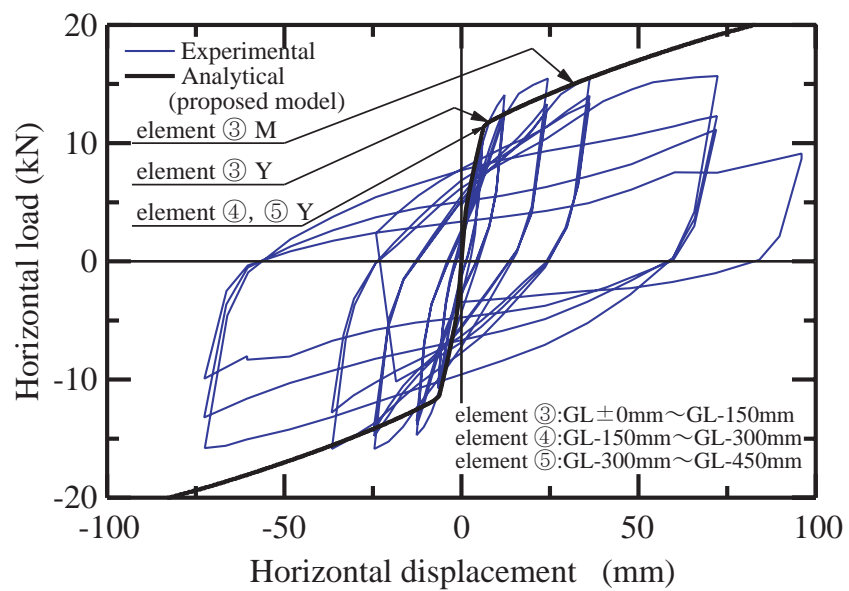

Fig. 8 Numerical simulation results obtained using the proposed model $(200 \mathrm{kPa})$
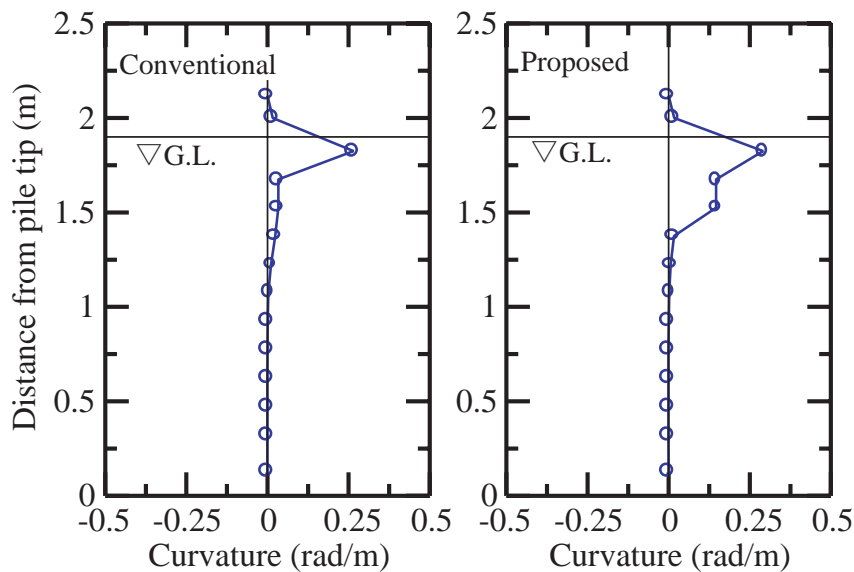

Fig. 9 Curvature diagrams obtained through numerical simulation

Figure 8 represents the results of simulation using the proposed model. It can be seen that displacement at the M-point is $5 \delta_{y}$, an improvement over the value calculated using the conventional model.

Figure 9 shows a curvature diagram. The damage region calculated using the proposed model is over a range as wide as the crack pattern observed through experiments, whereas the area obtained using the conventional model is concentrated on a narrow region.

Similar results are also obtained from other numerical simulation of the alternate loading experiments for RC piles supported by coil springs acting as imitation ground ${ }^{13)}$.

\section{Conclusions}

The conclusions of this study are as outlined below.

(1) The following points were confirmed through both triaxial compression testing on RC columns and alternate horizontal loading testing on RC piles:

* Underground RC piles have higher ductility than those under atmospheric conditions as they are subject to confining pressure from the subgrade.

* Although RC piles under atmospheric conditions show a plastic hinge area of approximately $1 D$, underground piles show a damage region as wide as 2 or $3 D$.

(2) We proposed a new method of evaluating the ductility of underground RC piles based on the experiments detailed above. Points to note are as follows:

* The effect of the confining pressure from the subgrade on the concrete core is expressed using the concept of the equivalent area ratio of the hoop reinforcements, as shown in Eq. (4).

* Measures to prevent the expansion of the plastic hinge (recommended among the safety measures of The Seismic Design Standard for Railway Structures) were waived.

(3) The validity of the proposed model was confirmed through numerical simulation for alternate horizontal loading tests on RC piles under the ground.

\section{Acknowledgment}

This research represents a part of the study results made possible by a subsidy from the Ministry of Land, Infrastructure and Transport.

\section{References}

1) Watanabe, T., Tanimura, Y., Takiguti, M. and Sato, T., "Evaluation method of deformation capacity related to damage conditions for reinforced concrete members," Journal of Materials, Concrete Structures and Pavements, JSCE, No.683/V-52, pp. 31-45, August 2001 (in Japanese).

2) Hoshikuma, J., Unjoh, S., Kawashima, K. and Nagaya, K., "A ductility evaluation of flexural reinforced concrete columns based on loading history and plastic curvature," Journal of Structural Engineering, JSCE, Vol.44A, pp. 877-888, March 1998 (in Japanese).

3) Asazu, N., Unjoh, S., Hoshikuma, J. and Kondoh, M., "Plastic hinge length of reinforced concrete columns based on the buckling characteristics of longitudinal reinforcement," Journal of Structural Mechanics and Earthquake Engineering, JSCE, No.682/I-56, pp. 177194, July 2001 (in Japanese).

4) Shirato, M., Kimura, Y. and Fukui, J., "A model with the swelling out of re-bar for cast in place pile and its application to estimate the effect of kinematic interaction on pile foundation," Journal of Structural Mechanics and Earthquake Engineering, JSCE, No.689/I57, pp. 153-172, October 2001 (in Japanese).

5) Japan Ministry of Transportation, The seismic design standard for railway structures. Maruzen Print Co., Ltd., Tokyo, Japan, 1999 (in Japanese).

6) Mander, J. B., Priestley, M. J. N. and Park, R., "Theoretical stress-strain model for confined concrete," Journal of the Structural Engineering, ASCE, Vol.114, No.8, pp.1804-1826, August 1988.

7) Shirato, M., "Computational seismic performance assessment of a pile foundation subjected to a severe earthquake," Dr. Eng. thesis, the university of Tokyo, 2004.

8) Vesic, A. B., "Bending of Beams Resting on Isotropic Elastic Solid," Journal of the Engineering Mechanics 
Division, ASCE, Vol.87, No. EM2, pp.35-53, April 1961.

9) Koda, M., Takemura, J. and Kusakabe O., "Modeling and evaluation of p-y curves single pile in sand," Journal of Geotechnical Engineering, JSCE, No.645/III-50, pp. 191-207, March 2000 (in Japanese).

10) Murono, Y., Murakami, M., Hatanaka, H. and Tanamura, S., "Study on characteristics of non-linear-p-y curve of single pile bent with soil deformation," Proceedings of the 11th Japan Earthquake Engineering Symposium, pp. 1293-1296, November 2002 (in Japanese).
11) Tatsuoka, F. and Kohata, Y., "Stiffness of hard soils and soft rocks in engineering applications," Proceedings of International symposium Pre-failure Deformations of Geomaterials, Balkema, Vol.2, pp.947-1066, 1994.

12) Hardin, B. O. and Richart F. E. Jr., "Elastic wave velocities in granular soils," Journal of the SMF Div., ASCE, Vol.95, No.SM6, pp.1531-1537, 1963.

13) Imamura, T., Murono, Y. and Nagao, T., "Evaluation of ductility for RC piles subjected to confining pressure in the ground," Journal of the $28^{\text {th }}$ JSCE Earthquake Engineering Symposium, JSCE, Vol. 28, Number of the paper 161 (CD-ROM), August 2005 (in Japanese). 